\section{Duplo sentido}

\section{lsabel Vidal}

[A]s peças bem montadas vão cortadas para não estragar a dentadura.

Bola de neve, 1935

\footnotetext{
${ }^{1} 0$ seu artigo $3 .{ }^{\circ}$ estabelece os objectivos da censura: "A censura terá somente por fim impedir a perversão da opinião pública na sua função de força social deverá ser exercida por forma a defendê-la de todos os factores que desorientem contra verdade, a justiça, a moral, a boa administração e 0 bem comum, e a evita que sejam atacados os principios fundamentais

da organização da sociedade".

${ }^{2}$ Nos anos iniciais, entre 1926 e 1933, os serviços estavam sob a tutela do Ministério do Interior e da Guerra, passando depois exclusivamente para o Ministério do Interior.
}

Isabel Vidal é licenciada em Antropologia e em Ensino de Português/Inglês para

o $3 .^{\circ}$ Ciclo e

Secundário, com vinte anos de experiência de ensino nas áreas de Geografia, História e Português. Prepara uma dissertação de mestrado em Estudos de Teatro, na Faculdade de Letras da

Universidade de Lisboa, sobre a actividade teatral portuguesa na década de trinta do século XX.
Na década de trinta do século $X X$, o panorama teatral português resumia-se à produção de tipos de espectáculo de identidade precisa, de onde se destacam dois: o teatro de declamação, que explorava os géneros de comédia e o drama, e o teatro de revista, de carácter popular, localizado em casas de espectáculos como o Teatro Maria Vitória, o Teatro Variedades ou o Teatro Apolo. 0 teatro era uma actividade comercial assumida, cujo sucesso dependia de estratégias concebidas para atrair o público e vender bilhetes.

Comparando a autoria dos textos de teatro de revista com os de teatro de declamação, verifica-se que, nos primeiros, predomina a autoria portuguesa e que um dos seus objectivos era o de serem actuais, constituindo um espaço onde eram reproduzidos discursos do quotidiano. Sobre eles, os autores imprimiam o registo de humor, que regressava às ruas sob a forma de slogans, anedotas e canções.

Cerca de sessenta autores de revista, individualmente ou em parcerias, produziam um tipo de texto dramático específico, crítico, satírico, francamente marginal em relação às directivas centrais que limitavam a liberdade de expressão.

Para melhor compreender o impacto que a censura tinha na actividade teatral é necessário perceber como esta se estruturava e como actuava relativamente aos originais propostos para a encenação. Será de esclarecer que num panorama artístico submetido à censura, o texto era o suporte sobre o qual se construía um espectáculo e por onde os censores começavam o seu trabalho. Mesmo assim, este estendia-se à actualização do texto em cena com a presença obrigatória de uma comissão de censores no ensaio geral e com o controlo dos espectáculos garantido por agentes de fiscalização.

As referências legais que regulamentavam o funcionamento das casas de espectáculos, na década de trinta do século $X X$, encontravam-se estabelecidas no Decreto n. 13564 (Regulamento dos teatros e de todas as outras casas de espectáculos, de 6 de Maio de 1927) e os textos dramáticos eram submetidos à Comissão de Censura Teatral, através da Inspecção-Geral de Espectáculos. Estes dois organismos orientavam-se por princípios estabelecidos no Decreto-Lei n. ${ }^{\circ} 11839$, de 5 de Julho de 1926, substituído pelo Decreto-Lei n. ${ }^{\circ} 12008$, de 29 de Julho do mesmo ano, e pelo Decreto-Lei n. ${ }^{\circ} 22469$, de 11 de Abril de 1933, decorrente da Constituição de Março desse ano. ${ }^{1}$
0 regulamento interno dos Serviços de Censura incidia a atenção nos temas a serem objecto de intervenção, entre os quais se destacam os seguintes: referências desprimorosas para o chefe de estado, referências a assuntos que se ligassem directamente à ordem pública, noticias de carácter político nacional e internacional, alusões à censura e matéria redigida em língua grosseira, imoral e injuriosa. A política internacional justificou a adição e o reforço de instruções no Regulamento dos Serviços de Censura, em 1936, e esclarecimentos através de circulares internas, em 1939, em ambos os casos, com a intenção de explicitar e de tornar mais eficaz a aplicação da lei.

Progressivamente, os temas que constituiam objecto de intervenção por parte do censor foram-se ampliando e especificando, mas nunca de uma forma suficientemente clara para definir uma intervenção concreta.

No teatro de revista, a lei acabou por ser aplicada de um modo incompleto e pouco eficaz, deixando passar conteúdos políticos e morais susceptiveis de corte. Globalmente, o que parece transparecer é a existência de duas situações concretas: cumplicidade e incompetência por parte dos censores.

0 que nos leva à hipótese desta cumplicidade é a incoerência dos cortes, permitindo, em contextos semelhantes, duplos resultados: a admissão e a supressão. Não é fácil entender esta incoerência ou dualidade de critérios. Por um lado, a admissão de alguns contextos favorecia a promoção popular de figuras políticas. Por outro, a admissão de outros leva a crer também na falta de capacidade para entender subtilezas de texto de carácter crítico que apenas pode ser explicada a partir da falta de preparação académica/erudita dos censores para compreender o alcance de truques de retórica e de jogos de palavras.

0 recrutamento inicial dos censores no âmbito militar ${ }^{2}$ que se detecta quando, nos processos, se associa o nome dos mesmos às suas patentes, poderá explicar as lacunas de identificação do alcance de alguns recursos estilísticos dos dramaturgos, nomeadamente no que diz respeito ao uso da conotação, do duplo sentido, ou ainda o alcance semântico de campos instituidos por determinados vocábulos, isolados ou em companhia de outros, traçando significados pretendidos para a produção de subtextos. Nota-se, nos censores, um esforço de intransigência no corte de soluções de diálogo integradas em modelos anteriormente experimentados, mas uma certa insegurança, 

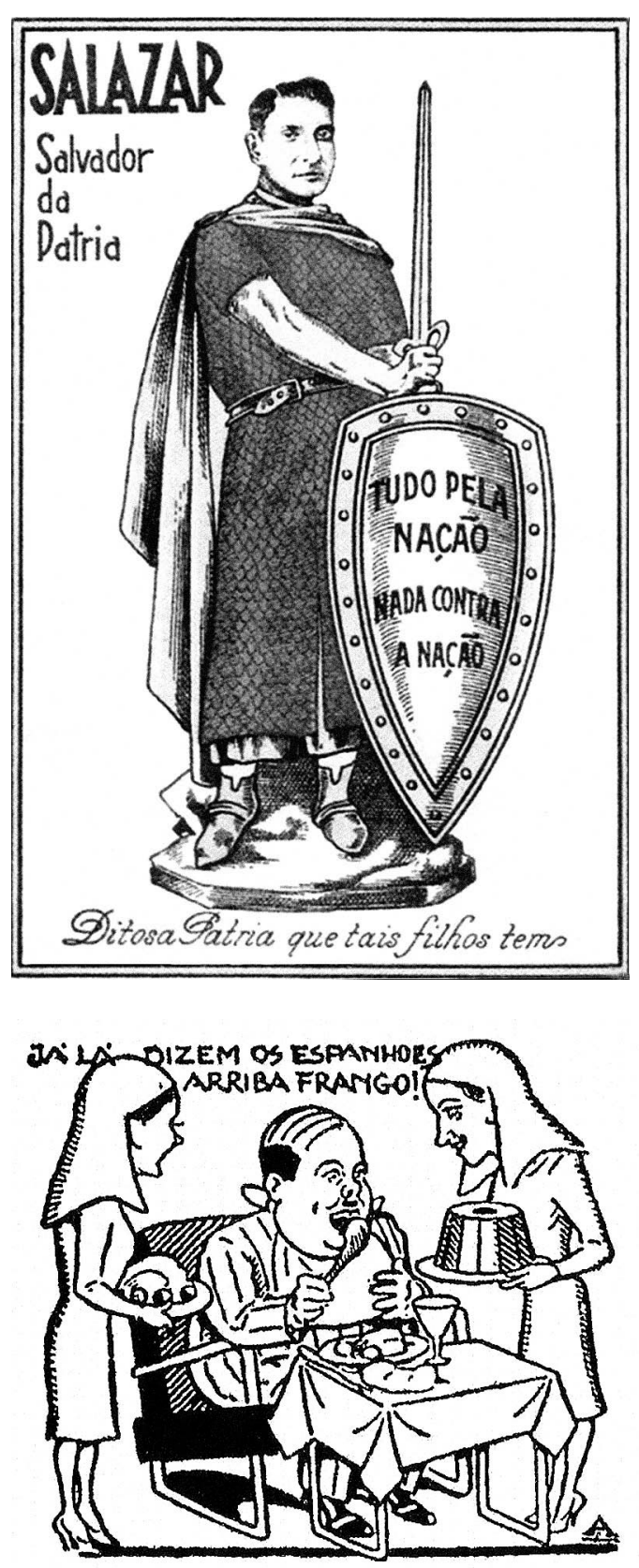

ou mesmo falta de capacidade de detectar os efeitos elocutórios de novas soluções.

Quanto aos cortes, estes incidiam em palavras ou expressões que pelo seu sentido directo designavam aspectos proibidos - "nacional", "pátria", "Salazar", "bandeira" -, mas também noutras cujo sentido figurado tinha conotações políticas bem conhecidas: "rolha", "tacho", "panelinha", ou "virar a casaca". A imoralidade era também banida pelo corte de palavras e expressões como "eunuco", "nádegas", "dar à luz", e outras a que a gíria masculina atribuía conotação sexual: "furar", "assinar", "montar". Simultaneamente, algumas construções de carácter metafórico, como "passar a mão pelo manjerico", eram autorizadas. Havia especial cuidado com palavras atribuiveis a figuras de estado, como "ferro" ou com palavras terminadas na sílaba "zar".

São frequentes os números que descrevem a vida politica em que os autores usam pistas demasiado evidentes

\section{Um exemplo de sátira à propaganda do regime: "Orador:... Aos nossos inimigos eu direi, como essa figura da lenda, \\ que coberta de malha se encosta ao escudo e ergue a espada. (Ao criado, que traz a travessa com a galinha) Vilão: chega-me cá essa galinha, que o resto já não cai, é obra minha", Milho Rei, 1935. 0 sublinhado foi a secção cortada pelo censor.}

e nelas os censores cortam a pista, mas deixam passar o contexto, em que era evidente a existência de um subtexto de crítica política e social.

A redacção dos textos do teatro de revista não era ingénua e procurava estratégias humorísticas obedecendo a um estilo próprio do género. Uma das estratégias, por exemplo, era a de situar a acção em contextos inocentes: uma sala de aula, uma loja, uma conversa entre vizinhos de bairro. Havia também uma consciência adquirida na experiência que determinava a apresentação de soluções para quadros que, à partida, evidenciavam a propensão ao corte. Algumas propostas eram de tal forma ousadas que se ofereciam ao corte, ao lado de outras menos fortes que acabavam por passar. Os autores foram desenvolvendo, assim, uma competência na escrita aliada à autocrítica e uma predisposição lúdica no acto criativo, redigindo variações do mesmo tema como propostas para a substituição dos quadros cortados, aprendendo com as soluções que acabavam por passar.

Os autores estavam conscientes de que o teatro de revista era para ser encarado como um negócio cujo sucesso dependia da afluência de público Os empresários estavam igualmente cientes da importância do texto, pois o espectáculo apoiado exclusivamente nas vertentes visual e musical não oferecia garantias suficientes de êxito. Deste modo, a sátira política e a linguagem picante tinham uma função que não podia ser completamente eliminada, sob o risco de afastar o público.

A década de trinta do século XX caracteriza-se pela repetição de um discurso crítico que pretende explicar a "crise do teatro", materializado, sobretudo, na falta de públicos. Tratava-se de uma ameaça real ao negócio do teatro. Poucas companhias independentes conseguiram manter uma actividade estável ao longo da década. Desta forma, uma intervenção cabal da censura nos textos terminaria certamente com um dos factores de atracção do público pelos espectáculos do teatro de revista: a possibilidade de ver a transgressão, mesmo que velada ou transformada em alegoria.

Os autores estavam atentos ao discurso do quotidiano, às interpretações populares das decisões politicas e às piadas brejeiras que animavam as vivências sociais. 0 que escrevessem nos textos iria reflectir aquilo que o público imaginava ver reproduzido no palco como a caricatura da realidade. 0 público encontraria no palco a reprodução de um discurso com o qual se identificaria, situado em ambiente lúdico, com o qual era possivel estabelecer uma
Uma caricatura de

Amarelhe usada para promover um espectáculo de revista e onde se pode ver um exemplo de uma técnica usada pelos dramaturgos para produzir humor 
José Galhardo

Alberto Barbosa

e Vasco Santana,

uma parceria de sucesso no teatro de revista dos anos trinta do século XX.
Um censor durante 0

ensaio geral de uma revista, provavelmente Ai-ló, no Teatro Avenida.

Ao seu lado estão os escritores Alberto Barbosa

e João Bastos,

O noticias ilustrado, 2 de Agosto de 1931 relação de cumplicidade transgressora sem consequências reais repressivas.

A experiência ao longo da década de implementação do regime do Estado Novo acabou por demonstrar que alguma permissividade dos censores também podia jogar a favor da ditadura, fazendo do cómico (em particular, no teatro de revista) um meio para se realizar a aceitação social das contrariedades proporcionadas pelo regime, situando a realidade no mundo da ficção, em ambiente ligeiro.

A crítica à situação nacional, o tratamento de assuntos políticos internacionais e a revisão histórica do período imediatamente anterior ao do regime de ditadura são objecto de forte contenção nas directivas dos Serviços de Censura. Contudo, podemos encontrá-los nos diálogos dos quadros de revista, em rábulas que os censores deixaram passar.

Por exemplo, a admissão da caricatura da figura do chefe de estado na personagem do Santo António demonstra que os censores sabiam que uma certa cumplicidade, ao contrário de favorecer a perversão receada, acabava por promover a figura do chefe de estado. Na revista Maria Cachucha (Teatro Apolo, 1934), o número musical "Santo António", com letra de Carvalho Mourão, usava o seguinte refrão: "Ai Santo António que és levado do demónio / Ai Santo António já que tudo alcanças / Já que és santo milagreiro vê se me arranjas dinheiro, / Endireita-me as finanças".

0 que levava os autores a enveredar pela sátira politica e pela imoralidade explícita, sabendo à partida, pela experiência, o que o censor não deixaria passar? Sabemos que os textos se apoiavam em soluções já experimentadas em revistas anteriores, pois uma das observações da crítica quanto à qualidade dos mesmos é o seu carácter repetitivo. Havia personagens, tipos, situações, diálogos e rábulas que se reutilizavam. Os autores socorriam-se de modelos de um arquivo de recursos dentro do género, considerados normais e representativos. Aplicavam variações dentro destes modelos inspirando-se em ditos de rua. Tratavase de uma originalidade artificial e consciente. A escrita era intencional e própria de um género.

Os autores mais populares eram protegidos pelo facto de trabalharem exclusivamente em textos de revista e persistiam, apresentando quadros de explícita transgressão, obviamente cortados. Era uma classe de enfants térribles dentro do grupo dos autores, aos quais se dava uma margem de desconto a bem da continuação do negócio
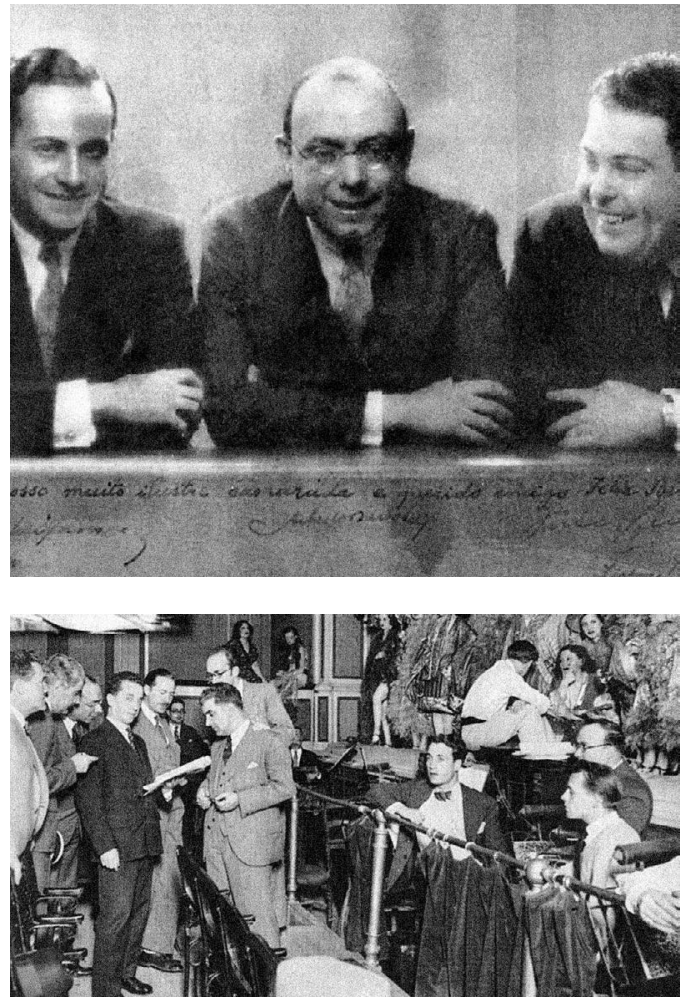

do teatro de revista. Eram pessoas estimadas e bem tratadas pela comunicação social, usadas pelo mecanismo de propaganda, uma espécie de bufões reconhecidos na sociedade aos quais quase tudo se podia desculpar.

Sabemos que uma percentagem elevada dos habitantes de Lisboa era proveniente de áreas rurais e procurava aprender a inserir-se no ambiente urbano. Cerca de metade da população de Lisboa era analfabeta e os mecanismos de comunicação oral revelavam-se fundamentais numa sociedade organizada em núcleos familiares, corporativos e de bairro. Neste contexto, o teatro de revista, para além do seu papel lúdico, centralizava discursos de actualidade e ensinava aos lisboetas as últimas anedotas, ditos e slogans que depois se repetiam na intimidade.

0 teatro de revista tinha uma função social a cumprir: era o lugar onde o seu público podia encontrar a transgressão que animava o espectáculo visual, coreográfico e musical associados a um tipo de humor que tinha, em Lisboa, uma forte receptividade. Era também o lugar de difusão de mensagens para aqueles que iam ao espectáculo à procura de referências sociais e de ditos espirituosos. Era esta função que alguns censores reconheciam e com a qual compactuavam parcialmente, deixando também passar a imagem de que, tal como estava estabelecido na Constituição de 1933, havia liberdade de expressão, mas que o seu exercício estava regulado por leis especiais para salvaguardar a integridade moral dos cidadãos 